\title{
BMJ Healthcare consultation and sick leave Open before and after neck injury: a cohort study with matched population-based references
}

\author{
Anna Jöud, ${ }^{1,2}$ Johanna Stjerna, ${ }^{3}$ Eva-Maj Malmström, ${ }^{3,4}$ Hans Westergren, ${ }^{3,5}$ \\ Ingemar F Petersson, ${ }^{1,2}$ Martin Englund ${ }^{1,2,6}$
}

To cite: Jöud A, Stjerna J, Malmström E-M, et al. Healthcare consultation and sick leave before and after neck injury: a cohort study with matched populationbased references. BMJ Open 2013;3:e003172.

doi:10.1136/bmjopen-2013003172

- Prepublication history and additional material for this paper is available online. To view these files please visit the journal online (http://dx.doi.org/10.1136/ bmjopen-2013-003172).

Received 8 May 2013 Revised 15 July 2013 Accepted 24 July 2013

${ }^{1}$ Department of Orthopedics, Clinical Sciences Lund, Lund University, Lund, Sweden Epi-centre Skåne, Skåne University Hospital, Lund, Sweden

${ }^{3}$ Department of

Rehabilitation, Skåne

University Hospital, Lund,

Sweden

${ }^{4}$ Department of

Otorhinolaryngology, Clinical

Sciences Lund, Lund

University, Lund, Sweden

${ }^{5}$ Department of Health

Sciences, Lund University,

Lund, Sweden

${ }^{6}$ Clinical Epidemiology

Research and Training Unit, Boston University School of Medicine, Boston,

Massachusetts, USA

Correspondence to Dr Martin Englund; martin.englund@med.lu.se

\section{ABSTRACT}

Objectives: Recent studies based on self-assessed data on exposure and outcome suggest a negative association between poor health before neck injury and recovery. Our aim was to study actual healthcare consultation and work disability before and after neck injury (whiplash).

Design: Cohort study with matched references studied prospectively and retrospectively via regional and national held registers.

Setting: Population-based study in Region Skåne,

Sweden (population=1.21 million) including all levels of healthcare.

Participants: 1443 participants aged $\geq 18$ (54\% women) with acute neck injury, Whiplash, (International Classification of Diseases-10-SE code S13.4*) in 2007 or 2008 and no such diagnosis since 1998. Each patient with a neck injury was assigned four randomly selected population references matched for age, sex and area of residence $(97 \%$ of the patients and $94 \%$ of the references were followed during the whole study period).

Primary and secondary outcome measures: We studied changes in healthcare consultations 3 years before to 3 years after diagnosis as well as sick leave episodes. Analyses were also stratified by preinjury frequency of consultation.

Results: Before the injury, the mean number of total consultations over 36 months among the neck injured $(n=1443)$ and references $(n=5772)$ was 9.3 vs 7.2 $(p<0.0001)$ and postneck injury 12.7 vs $7.8(p<0.0001)$. In the group of high-frequent consulters, there were more women compared with frequent and low-frequent consulters ( $70.6 \%$ vs $32.8 \%$; $p<0.0001)$. Among lowfrequent and frequent consulters preinjury $(n=967,67 \%$ of the cohort), $16 \%$ became high-frequent consulters attributable to the injury. The number of days of sick leave preinjury was correlated with the number of preinjury and postinjury consultations $(\mathrm{r}=0.47(99 \% \mathrm{Cl}$ 0.38 to 0.49$), r=0.32(99 \% \mathrm{Cl} 0.25$ to 0.37$))$.

Conclusions: People with a neck injury constitute a heterogeneous group. The preinjury level of healthcare consultation is associated with the postinjury level of consultation.

\section{ARTICLE SUMMARY}

\section{Article focus}

- On the basis of the self-assessed data on exposure and outcome, recent studies suggest a negative association between poor health before neck injury and recovery. Using observational data in a population setting, our aim was to study actual healthcare consultation and work disability before and after neck injury (whiplash).

Key messages

- People with a neck injury constitute a heterogeneous group, including, for example, lowfrequent consulters and high-frequent consulters before the injury.

- The preinjury level of healthcare consultation is associated with the postinjury level of consultation.

Strengths and limitations of this study

- We performed a large-scale population-based cohort study with matched references drawn from the general population of 1.2 million people followed for 6 years.

- Our use of register-based data enabled us to study outcome and exposure without influence of recall-bias in injured cases and references.

- A limitation of the study is potential misclassification of injury, although the injury code used to identify cases primarily is connected to the whiplash injury mechanism; other trauma mechanisms may be included as well.

\section{INTRODUCTION}

One common cause for trauma resulting in pain and dysfunction of the neck is the rearimpact car crash. ${ }^{1}$ The so-called whiplash trauma mechanism may result in injury to several soft-tissue structures present in the neck, for example, facet joints capsule, ${ }^{2}$ stabilising muscles ${ }^{3}$ and intervertebral discs. ${ }^{4} 5$ The symptoms after such trauma are heterogeneous as well as the recovery rate. ${ }^{6} \mathrm{Up}$ to 
$50 \%$ report an incomplete recovery ${ }^{7}$ and about $30 \%$ remain moderately or severely disabled. ${ }^{8}{ }^{9}$ Long-lasting musculoskeletal symptoms and consequences such as neck pain, arm-shoulder pain and reduced mobility are frequently reported after the trauma. ${ }^{10}$ Common psychological symptoms after whiplash trauma are depression, anxiety and post-traumatic stress syndrome. ${ }^{11}{ }^{12}$ Additionally, headache, dizziness and tinnitus are frequently reported. ${ }^{13-15}$

The post whiplash trauma course is difficult to predict due to the wide range of traumatic event types, individual symptom presentations, progress in recovery and the heterogeneous healthcare and follow-up systems. ${ }^{16}{ }^{17}$ The prognostic factors involve pretrauma risk factors ${ }^{17} 18$ as well as postinjury health factors. The postinjury health factors include the level of initial neck pain, cervical range of motion directly after the trauma, compensation certificates, type of treatment and beliefs which have been shown to improve and halter the rehabilitation process. ${ }^{17}{ }^{19-26}$ Most of the collision variables reported have been shown to be not associated with the prognosis. ${ }^{17} 1827$ Previous pain experiences, psychological distress as well as the socioeconomic situation and education have been reported to negatively influence recovery to various degrees. ${ }^{17-19}$ Recent studies have reported links between preinjury and postinjury selfreported healthcare consultation and health status. ${ }^{28-30}$

From the perspective of the society, healthcare consumption and return to work are important outcomes. ${ }^{31}{ }^{32}$ In Region Skåne, located in southern Sweden, there is a possibility to study patients' actual healthcare consultations and sick leave episodes using longitudinal data from independent sources both before and after neck-injury diagnosis. Comparing the actual consultation pattern before and after injury diagnosis may provide insights and better understanding of the course and of the prognostic factors. Hence, the objective was to study healthcare consultation and work disability before and after neck injury (whiplash).

\section{MATERIAL AND METHODS}

\section{Data sources}

Healthcare consultations

We used data from the Skåne Healthcare Register (SHR), which contains routine prospectively ascertained information from computerised medical records, as well as from administrative application sources, on all healthcare in Region Skåne, the southernmost part of Sweden (total population $2008=1214758$, ages $\geq 18$ years $=$ 964 237). SHR includes data on the type of consultation (eg, public/private, primary, specialist or hospitalisations), type of healthcare professional (physician, nurse, physiotherapist, etc), date of consultation, diagnostic codes and surgical and/or injury codes where relevant. The physicians' diagnostic codes are automatically transferred from the medical records. Since 1998, diagnoses are classified according to the Swedish version of the
International Classification of Diseases and Related Health Problems system, V.10 (ICD-10-SE). Diagnoses from private practitioners are not automatically transferred to SHR, and therefore only cases receiving a diagnosis within the public care are included in this study.

\section{Work disability}

The Swedish social insurance is administered by the Swedish Social Insurance Agency (SSIA) and covers everyone who lives and/or works in Sweden. All sick leave periods exceeding 14 days and all disability pension payments are administered and registered by the SSIA. The SSIA register includes dates, type and amount of sick leave and disability pension as well as diagnostic codes.

\section{Educational level}

Data on educational level were drawn from the Longitudinal Integration Database for Health Insurance and Labour Market Studies (LISA). LISA includes data on, for example, occupation and educational level for the Swedish population. Here educational level is divided into three groups based on the number of years of formal education that an individual has had: lower (up to 9 years), medium (10-12 years) and higher education (more than 12 years). We linked data from the SHR, SSIA and LISA with the Swedish population register using the personal identification number, a unique 10-digit number assigned to all Swedish residents, in order to only include residents of Region Skåne.

\section{Study cohorts}

Neck-injury cohort

We identified all adult (18 years or older) residents of Region Skåne who had been diagnosed with neck injury, Whiplash, ICD-10-SE code S13.4*, by a physician in an acute setting (emergency ward, acute non-planned visit to physician in either specialist or primary care) between 1 January 2007 and 31 December 2008 with no previous record of an S13.4* diagnosis since 1998. In the Swedish ICD-10 version, S13.4 is further subdivided for Whiplash-associated disorder 1-3 by the letter A-C (ie, S13.4A). We use the term neck injury throughout. We excluded all cases with any record of an injury involving the head and/or neck (ICD-10-SE chapter S00-S19) between 1998 and 2007 up until the month before diagnosis (figure 1). We refer to this month as the 'screening' month to reduce the possibility of excluding participants with acute neck injuries that were initially labelled differently, that is, had a somewhat delayed S13.4* diagnosis. The participants were followed for 6 years, from 3 years prior to the 'screening' month until 3 years after the neck injury (figure 2) or until relocation or death. Data on work disability were available 3 years before up until 2 years after the neck injury. 


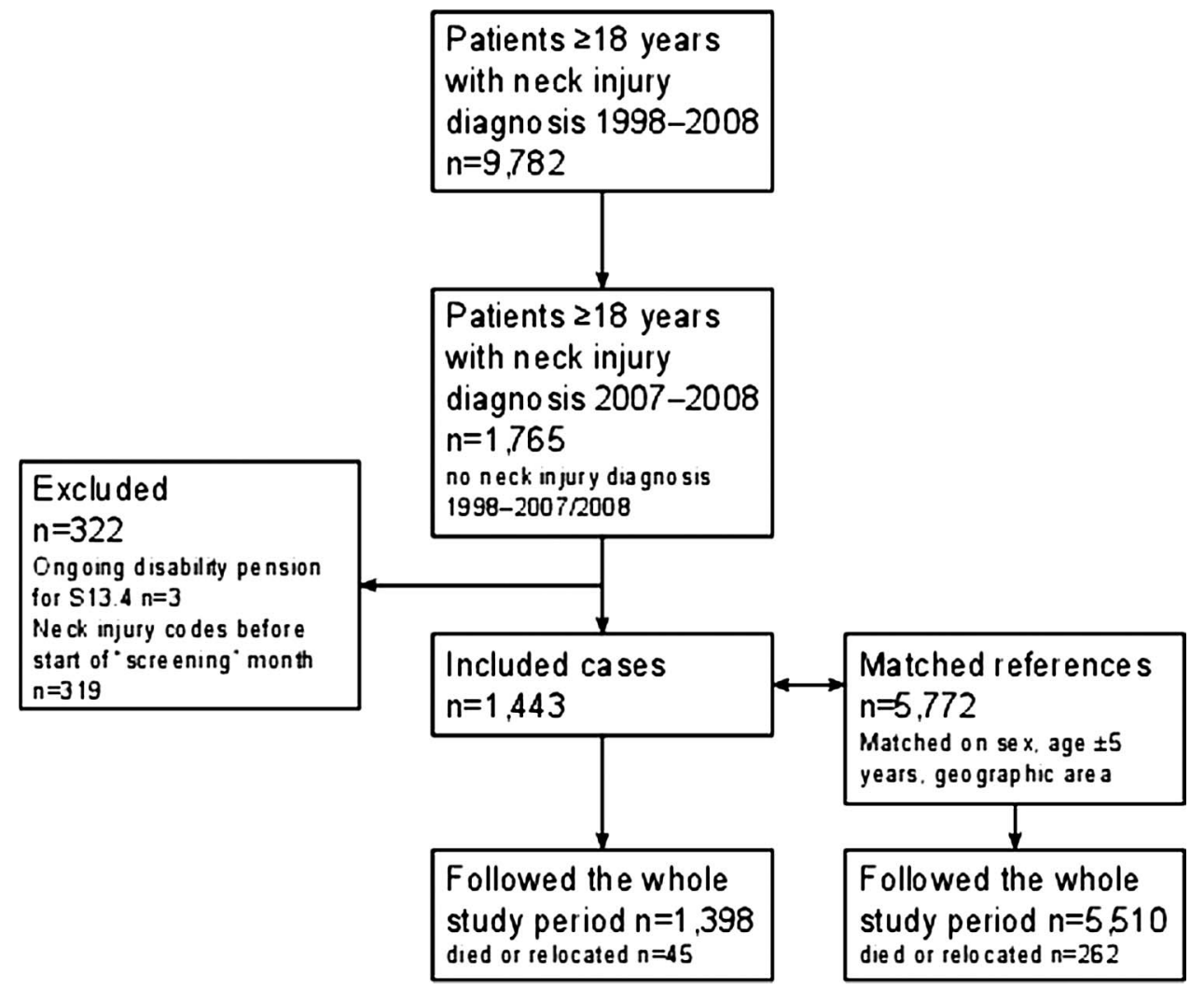

Figure 1 Flow chart of study inclusion.

\section{Reference cohorts}

To be able to compare the healthcare pattern and sick leave pattern of the patients with neck injury with the general population, we also assigned each case with four reference participants randomly sampled from the Swedish population register matched for birth year, sex and area of residence (figure 1 and table 1). We considered this reference group to be our primary references (References 1).

As part of the sensitivity analyses, we also sampled two alternative reference cohorts. First, we hypothesised that educational level would affect the healthcare consultation frequency. Hence, we created a second reference cohort which was additionally matched for educational level (References 2). Second, for the third reference cohort (References 3), we additionally required all participants to have had at least one healthcare consultation in the same year as the case had its neck-injury diagnosis (table 1). The reason for this was to evaluate the effect on outcomes using a reference cohort with a propensity

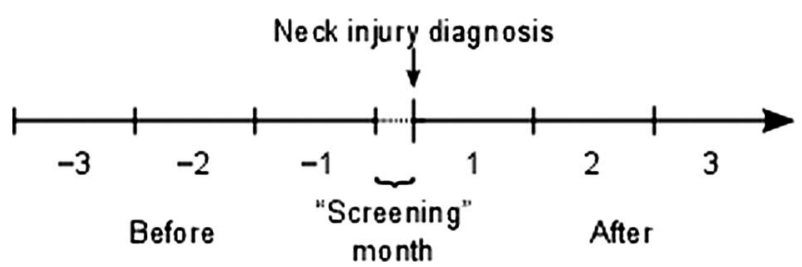

Figure 2 Schematic figure over the 6-year study period; 3 years before until 3 years after neck-injury diagnosis. to consult healthcare (similar to our patients with neck injury). If not stated otherwise, all comparative analyses are with the primary reference cohort.

\section{OUTCOMES}

\section{Healthcare consultations}

We studied the number of consultations overall and the number of consultations to physicians and physiotherapists, respectively. Based on the median (quartile $1(\mathrm{Q} 1)$; quartile $3(\mathrm{Q} 3)$ ) number of consultations in the reference group (Reference 1) in the 3-year period prior to the neck injury, we specified cut-offs to define lowfrequent ( $\leq 1$ consultation), frequent $(=2-8$ consultations) and high-frequent consulters ( $\geq 9$ consultations). We used this categorisation to perform stratified analyses. We present the numbers per year throughout with one exception; to study the number of consultations in detail after injury, we display the mean number of consultations within each subgroup by quarters of a year starting with the 3 months preinjury. Lastly, we also assessed the absolute portion of those with neck injury who went from being a low-frequent to a high-frequent consulter due to the injury (attributable risk (AR)).

Further, we aimed to study physician consultations specifically associated with musculoskeletal disorders (ICD-10 chapter XIII), headache (ICD-10 codes M53.1, G44.0, G44.3, F45.4, G44.2, R51, G44.1), dizziness (ICD-10 codes H81.0, H81.1, H81.2, H81.3, H81.4, H81.8, H81.9, R42.9, F40.0) and tinnitus (ICD-10 code H93.1). Finally, selected 
Table 1 Matching variables for the three reference groups and characteristics of the study groups

\begin{tabular}{|c|c|c|c|c|}
\hline & $\begin{array}{l}\text { Cases } \\
n=1443\end{array}$ & $\begin{array}{l}\text { Reference } 1 \text { (primary) } \\
\mathrm{n}=5772\end{array}$ & $\begin{array}{l}\text { Reference } 2 \\
\mathrm{n}=5772\end{array}$ & $\begin{array}{l}\text { Reference } 3 \\
\mathrm{n}=5770\end{array}$ \\
\hline Number of matched references per case & & 4 & 4 & $4^{*}$ \\
\hline \multicolumn{5}{|l|}{ Matched on } \\
\hline Sex & & $\checkmark$ & $\checkmark$ & $\checkmark$ \\
\hline Age ( \pm 5 years) & & $\checkmark$ & $\checkmark$ & $\checkmark$ \\
\hline Area of residence & & $\checkmark$ & $\checkmark$ & $\checkmark$ \\
\hline Observation time & & $\checkmark$ & $\checkmark$ & $\checkmark$ \\
\hline Educational level & & & $\checkmark$ & $\checkmark$ \\
\hline Healthcare consultation in the year of case inclusion & & & & $\checkmark$ \\
\hline Women, n (\%) & $784(54)$ & $3136(54)$ & $3136(54)$ & $3136(54)$ \\
\hline Age, mean (SD) & $38(14.6)$ & $38(14.5)$ & $38(14.7)$ & $38(14.8)$ \\
\hline \multicolumn{5}{|l|}{ Educational level, n (\%) } \\
\hline Low ( $\leq 9$ years) & $246(17.0)$ & $925(16.0)$ & & \\
\hline Medium (10-12 years) & $785(54.4)$ & 2935 (50.8) & & \\
\hline High (>12 years) & $397(27.5)$ & $1791(31.0)$ & & \\
\hline Missing & $15(1.0)$ & $121(2.1)$ & & \\
\hline
\end{tabular}

mental conditions here defined as psychological distress; depression (ICD-10 code F32), anxiety (ICD-10 code F41) and stress (ICD-10 code F43) were studied. These conditions have all been associated with the disability period after neck injury. ${ }^{14}$ The proportion of participants assigned diagnoses from the different disease groups, as well as the mean number of consultations, is presented.

\section{Work disability}

Sick leave is defined as days with sickness benefit registered by the SSIA. In Sweden, you are entitled to sickness benefit when you cannot work due to an illness or injury. Sickness benefit covers everyone who legally works in Sweden or who is registered as unemployed. It is generally limited to 1 year but can be extended. You receive compensation from day 2 and if you are employed, your employer will pay sick pay for days 2-14 and from day 15 you receive sickness benefit. If your work ability is permanently reduced by at least $25 \%$, you can receive a disability pension. Sick leave and disability pension can be granted for $100 \%, 75 \%, 50 \%$ or $25 \%$ of a working day depending on the extent to which your work ability is reduced. We computed the proportion on sick leave and disability pension and net sick days.

Net sick days (full-time sick days) are the total number of days for which sickness benefit or disability pension payment is received from the SSIA, multiplied by the extent of the sick leave or disability pension for each day (eg, 20 sick days with $25 \%$ of a day extent are equal to 5 net sick days). We compared the number of net sick days between cases and references as well as between the different subgroups.

\section{Statistical analysis}

We display the mean numbers of consultations and sick days including 99\% CI, although analyses based on means, medians and as count numbers have been conducted and are presented throughout. For median values (Q1; Q3), please see online supplementary tables S1 and S2. Differences in the number of consultations and sick days between patients with neck injury and references were determined by the Jonckheere-Terpstra test and the Mann-Whitney $U$ test. Differences within patients with neck injury between subgroups (low-frequent/frequent/high-frequent consulters) were analysed by the negative binomial regression, taking the underlying distribution in mind, adjusting for age and sex. Student t test, taking the equal variance and unequal sample size into account, was used to analyse differences between groups regarding age, while $\chi^{2}$ analysis was used to compare the distributions of education, sex, level of consultation and proportion of patients with neck injury who consulted for different diseases and proportion with work disability. Pearson's correlation coefficient $(r)$ was computed for the association between the number of sick leave days and the number of consultations both preinjury and postinjury. We used Fischer's z transformation to compute 99\% CI around the correlation coefficient. AR for change between consultation level groups preinjury to postinjury explained by the injury diagnosis was calculated as the risk in the group of patients with neck injury minus the risk in the reference group. Additionally, we computed risk ratios (RR) for patients with injury switching groups after injury compared with the references. This was carried out for the low, low and frequent and frequent consulter's preinjury, respectively. Owing to the multiple tests performed, we considered a p value of 0.01 or less to be statistically significant. All analyses were performed using SAS software V.9.3 (SAS Institute Inc, Cary, North Carolina, USA).

\section{Ethics statement}

The study was approved by the Regional Ethical Review Board in Lund (2011-431). Only register-data made 
Figure 3 Mean number of healthcare consultations for all types of healthcare, physican care and physiotherapist care of those with neck injury and of three different reference cohorts (see Methods section).

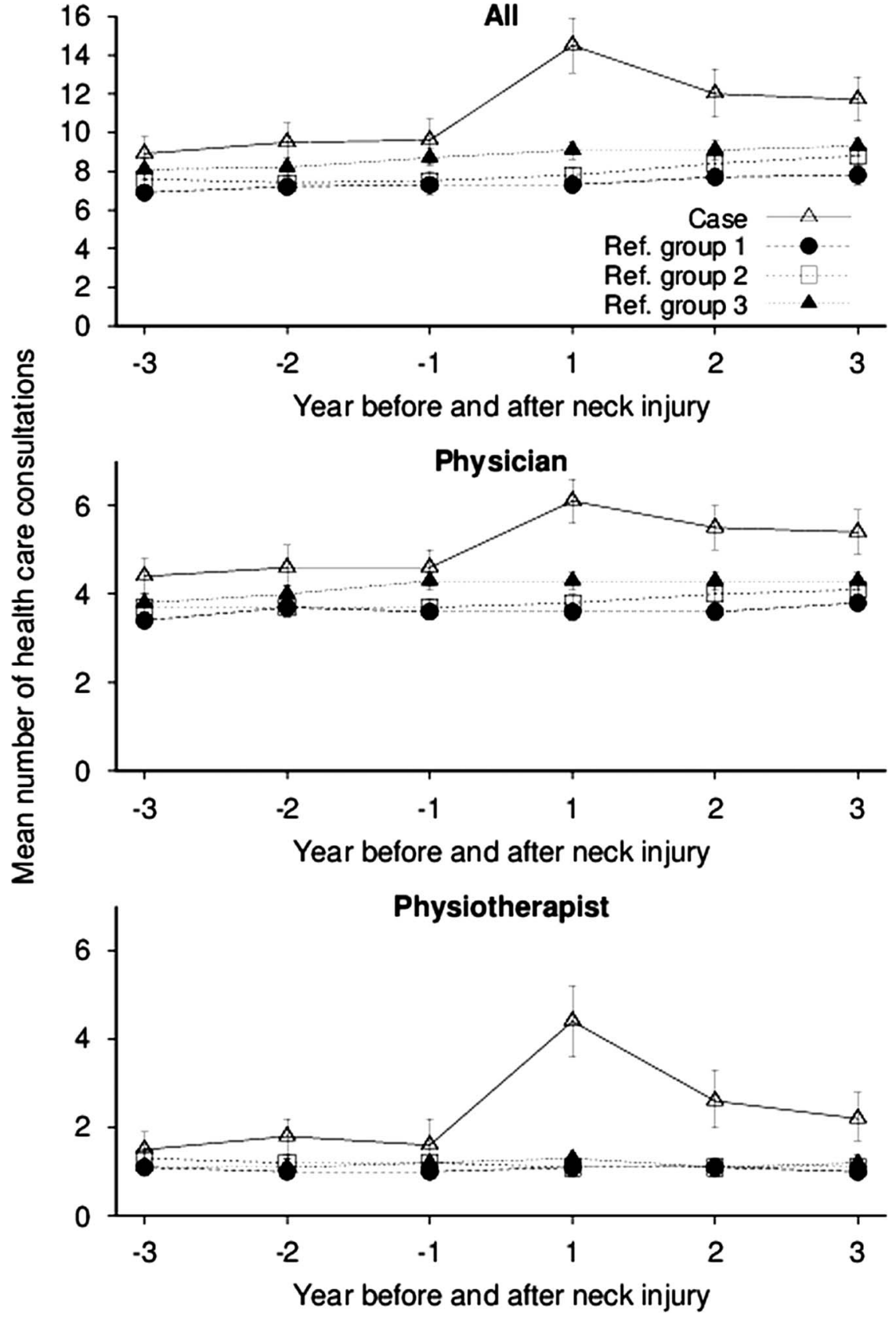

anonymous were used for analyses. The individuals in the cohort were informed of the study and offered 'opt-out' via regional news press, a process sanctioned by the Ethical Review Board.

\section{RESULTS}

\section{Cohort characteristics}

Between 1 January 2007 and 31 December 2008, 1443 adult residents ( $54 \%$ women) were diagnosed with neck injury (ICD-10 code S13.4) by a physician in an acute, non-planned visit and fulfilled our eligibility criterion (no registered head/neck injury between 1998 and 2007 up until the month before diagnosis; figures 1 and 2). The mean (SD) age at diagnosis was 38 (14.6) years (table 1). In the neck injury group, $55 \%$ of patients had been diagnosed at an emergency department, $39 \%$ at an acute visit in primary care and $7 \%$ at an acute visit in specialist care. During the follow-up period, $11.8 \%$ had consulted a specialist at a rehabilitation clinic and $4.4 \%$ had seen a neurologist or a neurosurgeon.

\section{Healthcare consultations}

Over the 6-year study period, the neck-injury cohort had significantly more healthcare consultations, the 3-year period before injury, than each of the three different reference groups $(p<0.0001)$. After adding education as a matching variable (Reference 2), the difference between those with neck injury and references remained significant but decreased slightly as did adding the criterion of having had at least one healthcare consultation 
to be an eligible reference participant (Reference 3; figure 3).

In the stratified analyses, when analysing differences between patients with neck injury and the primary reference group, the mean age was higher in those with neck injury and primary references of high-frequent consulters compared with their corresponding low-frequent consulters (41 vs 35 years in cases, $\mathrm{p}<0.0001$ ). Women were overrepresented in the group of high-frequent consulters and under-represented in low-frequent consulters, both among patients with neck injury and their references $(p<0.0001$; table 2$)$. The consultation frequency curves of the three subgroups (preinjury; lowfrequent, frequent and high-frequent consulters) had a similar shape and they remained clearly separated from each other even after the injury (figure 4). The number of consultations differed between the subgroups, preinjury and postinjury, after adjusting for age and gender $(\mathrm{p}<0.0001$, data not shown). The level of education did not differ between these three subgroups $(\mathrm{p}=0.6$; table 2).Those with neck injury consulted, on average, more than the references did, both before and after the neckinjury diagnosis $(p<0.0001$; figure 3$)$. The proportion of participants who were classified as low-frequent consulters among those with neck injury vs reference participants prior to the neck injury was 27 vs $35 \%(\mathrm{p}<0.0001)$.

\section{Diagnoses}

The diagnoses of headache, dizziness and tinnitus became more frequent especially after the neck injury, particularly among the low-frequent consulters, not only in the number of cases diagnosed but also in the number of consultations postneck injury (both $\mathrm{p}<0.0001)$. The proportion of cases diagnosed with psychological distress or musculoskeletal disorders also increased (table $3, \mathrm{p}<0.0001$ ). The low and frequent consulters were the group that changed the most not only in terms of the proportion of cases diagnosed with the particular disease but also the mean number of consultations per patient, while the high-frequent consulters changed the least in both aspects.
Work disability

On the day of diagnosis of neck injury, 96 participants of the cases $(6.7 \%)$ were on disability pension, primarily connected to the two ICD-10 chapters of musculoskeletal disorders (51\%) and mental disorders (30\%; table 4). Among the reference cohort, $5.8 \%$ were on disability pension, most typically due to mental disorders $(35 \%)$ and musculoskeletal disorders (28\%; figure 5). Among the cases and references eligible for sick leave (not on full-time disability pension), the mean number of sick days was higher in the cases than in the references both before and after the neck injury $(\mathrm{p}=0.0002$ and $<0.0001)$ The number of mean sick leave days before neck injury was correlated to the number of healthcare consultations before ( $\mathrm{r}=0.47$ (99\% CI 0.38 to 0.49 ) and after injury ( $\mathrm{r}=0.32$ (99\% CI 0.25 to 0.37$)$ ). The correlation was seen in all 3 years after the neck injury $(\mathrm{r}=0.31$ (99\% CI 0.24 to 0.36$), \mathrm{r}=0.30 \quad(99 \%$ CI 0.23 to 0.35 ) and $\mathrm{r}=0.22$ (99\% CI 0.15 to 0.28$)$ ).

The number of sick days before neck injury was different in the low-frequent, frequent and high-frequent groups of consulters, taking age and gender into account $(\mathrm{p}<0.0001$, data not shown $)$.

\section{Changes over time}

Of those with neck injury defined as low-frequent consulters before neck injury ( $\mathrm{n}=384), 19.2 \%$ switched to become high-frequent consulters in the year after diagnosis of neck injury (figure 6). The corresponding proportion for the references was $8.5 \%$. The RR for changing from a low-to-high frequent consulter 1 year after injury was 2.27 (99\% CI 1.63 to 3.15 ), and the increased risk was seen over the 3-year period following neck injury (table 5). Of those with neck injury defined as low-frequent or frequent-consulter consulters before neck injury, $31.9 \% \quad(n=41)$ switched to become highfrequent consulters in the year after diagnosis of neck injury. The corresponding proportion for the references was $15.9 \%$. Hence, the AR was $16 \%$. The increase in consultations in this subgroup was largely explained by an increased number of consultations with physiotherapists.

Table 2 Characteristics of those with neck injury and the primary reference (reference 1) cohort by their preinjury consultation level

\begin{tabular}{|c|c|c|c|c|c|c|}
\hline & \multicolumn{2}{|c|}{ Low-frequent } & \multicolumn{2}{|l|}{ Frequent } & \multicolumn{2}{|c|}{ High-frequent } \\
\hline & $\begin{array}{l}\text { Cases } \\
n=384\end{array}$ & $\begin{array}{l}\text { References } \\
n=2001\end{array}$ & $\begin{array}{l}\text { Cases } \\
n=583\end{array}$ & $\begin{array}{l}\text { References } \\
n=2287\end{array}$ & $\begin{array}{l}\text { Cases } \\
n=476\end{array}$ & $\begin{array}{l}\text { References } \\
n=1477\end{array}$ \\
\hline Women, n (\%) & $126(32.8)$ & 727 (36.3) & $322(55.2)$ & $1328(58.0)$ & $336(70.6)$ & $1081(73.0)$ \\
\hline Age, mean (SD) & $35(12.1)^{*}$ & $36(12.4)^{\star}$ & 37 (14.9) & 37 (14.6) & $41(15.4)^{\star}$ & $42(16.2)^{*}$ \\
\hline \multicolumn{7}{|l|}{ Educational level, n (\%) } \\
\hline Low ( $\leq 9$ years) & $58(15.1)$ & $257(12.8)$ & $91(15.6)$ & $332(14.5)$ & $83(17.4)$ & $336(22.7)$ \\
\hline Medium (10-12 years) & $213(55.5)$ & $1019(60.0)$ & $313(53.7)$ & $1187(51.9)$ & $265(55.7)$ & 729 (49.2) \\
\hline High (>12 years) & $109(28.4)$ & 667 (33.3) & $174(29.8)$ & 719 (31.4) & $127(26.7)$ & 405 (27.3) \\
\hline Missing & $4(1.0)$ & $58(2.9)$ & $5(0.9)$ & 49 (2.2) & $1(0.2)$ & $7(0.8)$ \\
\hline
\end{tabular}


Figure 4 Mean number of healthcare consultations after neck injury for all types of healthcare, physican care and physiotheraphist care of those preinjury consultation level; low-frequent $(n=384)$, frequent $(n=583)$ and high-frequent $(n=476)$. with neck injury stratified by their

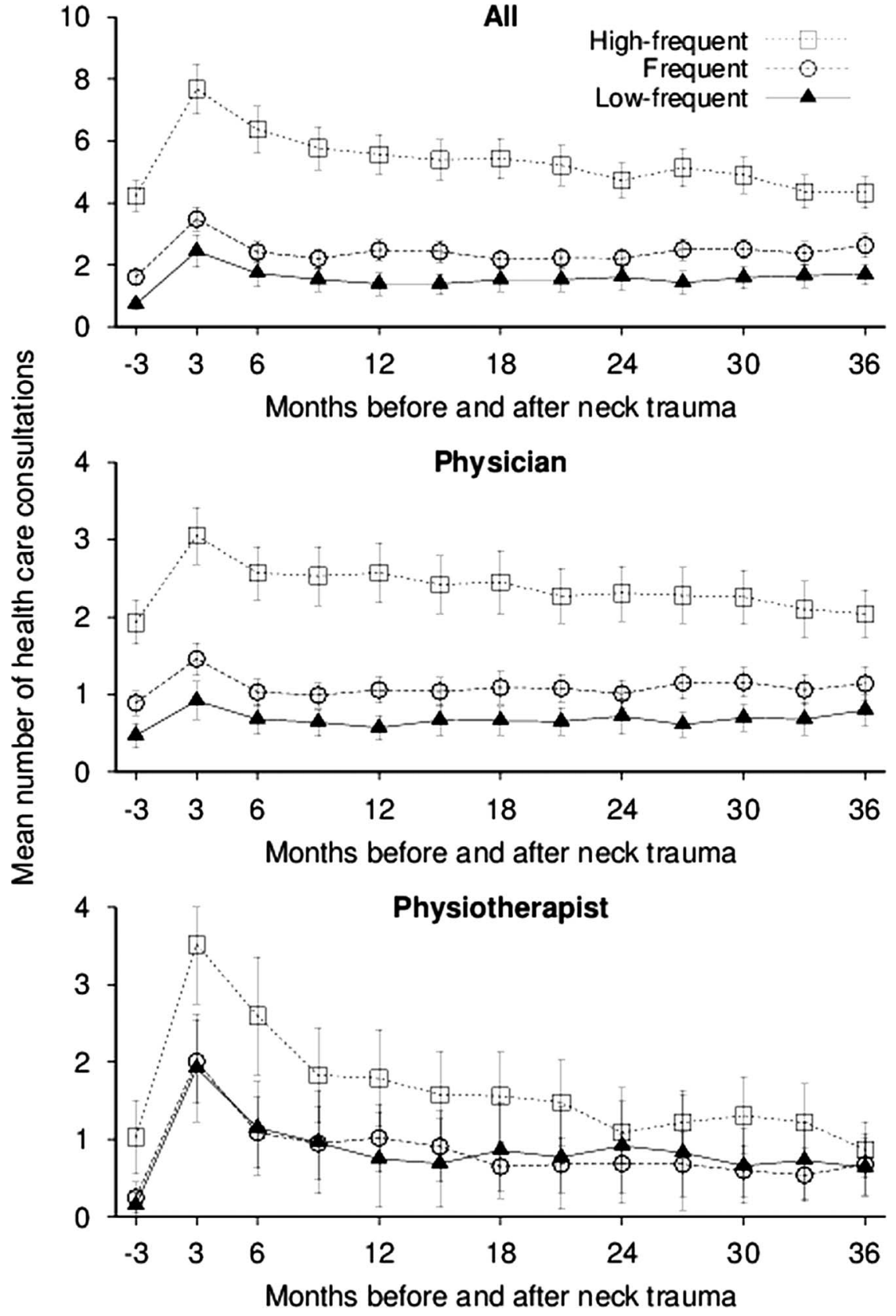

Among the low-frequent cases, the patients becoming frequent or high-frequent consulters after diagnosis of injury were also the group in which the mean annual number of sick days increased the most, from 16 days ( 3 years before diagnosis) to 32 sick leave days ( 2 years after; $\mathrm{p}<0.0001$; data not shown).

\section{DISCUSSION}

People with a neck injury constitute a heterogeneous group. We found increased healthcare consultation frequency and sick leave associated with acute neck injury regardless of the preinjury consultation rates. It is noteworthy that about $16 \%$ of the transition from low or frequent consulters preinjury to a high-frequent consultation pattern in the year after diagnosis could be attributed to the injury, and this pattern persisted, although slightly declining up to at least 3 years. However, in a subgroup of patients, high levels of healthcare consultations were noted already long before the diagnosis of neck injury

Given the expected heterogeneity of the patient category, our aim was to study health care consultation patterns before and after neck injury with the patients' preinjury consultation frequency in mind. In a recent study, Kasch $e t a l^{3}$ have presented a way of early stratification of patients with acute neck injury based on a risk score in relation to chronicity and work disability. Prior consultation frequency may serve as an additional variable for risk assessment of patients diagnosed with neck injury. 
Table 3 Proportion of cases and primary references (reference 1) who have consulted a physician due to different diagnostic chapters (ICD-10) before and after neck-injury diagnosis and mean numbers of consultation per participant consulting

\begin{tabular}{|c|c|c|c|c|c|c|c|c|c|c|c|c|}
\hline \multirow{3}{*}{ Year* } & \multicolumn{4}{|c|}{ Low-frequent } & \multicolumn{4}{|l|}{ Frequent } & \multicolumn{4}{|c|}{ High-frequent } \\
\hline & \multicolumn{2}{|l|}{$\begin{array}{l}\text { Cases } \\
n=384\end{array}$} & \multicolumn{2}{|c|}{$\begin{array}{l}\text { References } \\
n=2001\end{array}$} & \multicolumn{2}{|l|}{$\begin{array}{l}\text { Cases } \\
n=583\end{array}$} & \multicolumn{2}{|c|}{$\begin{array}{l}\text { References } \\
\mathrm{n}=2287\end{array}$} & \multicolumn{2}{|l|}{$\begin{array}{l}\text { Cases } \\
n=476\end{array}$} & \multicolumn{2}{|c|}{$\begin{array}{l}\text { References } \\
n=1477\end{array}$} \\
\hline & Per cent & Mean & Per cent & Mean & Per cent & Mean & Per cent & Mean & Per cent & Mean & Per cent & Mean \\
\hline \multicolumn{13}{|c|}{ Diseases of the musculoskeletal system and connective tissuet } \\
\hline Year-3 & 7.0 & 1.4 & 3.9 & 1.4 & 11.7 & 1.4 & 7.9 & 1.4 & 27.1 & 2.7 & 16.7 & 2.5 \\
\hline Year-2 & 1.3 & 1.2 & 0.8 & 1.3 & 10.5 & 1.4 & 9.1 & 1.3 & 33.8 & 2.8 & 22.7 & 2.2 \\
\hline Year-1 & 5.5 & 1.5 & 5.8 & 1.5 & 10.6 & 1.8 & 11.2 & 1.5 & 26.9 & 2.5 & 21.4 & 2.4 \\
\hline Year 1 & 13.8 & 2.0 & 4.1 & 2.0 & 18.2 & 2.0 & 10.0 & 1.7 & 35.5 & 3.3 & 20.4 & 2.4 \\
\hline Year 2 & 13.0 & 3.1 & 5.3 & 1.6 & 14.8 & 2.3 & 9.0 & 1.9 & 28.8 & 3.3 & 18.6 & 2.3 \\
\hline Year 3 & 10.7 & 3.1 & 6.3 & 1.8 & 17.8 & 3.0 & 12.0 & 1.8 & 29.8 & 3.5 & 21.5 & 2.6 \\
\hline \multicolumn{13}{|c|}{ Psychological distressł } \\
\hline Year-3 & 1.6 & 2.8 & 0.5 & 1.3 & 2.9 & 1.8 & 2.7 & 3.0 & 13.4 & 4.3 & 10.1 & 2.9 \\
\hline Year-2 & 0.8 & 1.0 & 0.0 & 0.0 & 3.4 & 1.5 & 2.5 & 2.6 & 14.9 & 4.5 & 11.4 & 3.2 \\
\hline Year-1 & 1.0 & 4.8 & 0.5 & 1.7 & 4.6 & 2.8 & 2.0 & 2.8 & 13.4 & 4.3 & 10.7 & 3.8 \\
\hline Year 1 & 3.1 & 3.8 & 1.1 & 2.3 & 5.7 & 3.4 & 1.6 & 2.3 & 13.9 & 4.5 & 7.9 & 4.3 \\
\hline Year 2 & 4.7 & 1.9 & 0.9 & 4.9 & 4.8 & 2.8 & 2.6 & 3.1 & 14.5 & 3.8 & 8.5 & 3.0 \\
\hline Year 3 & 4.7 & 3.1 & 1.7 & 1.9 & 6.5 & 4.3 & 4.0 & 2.9 & 10.3 & 2.6 & 8.6 & 2.7 \\
\hline \multicolumn{13}{|c|}{ Headache, dizziness and tinnitus§ } \\
\hline Year -3 & 1.0 & 1.0 & 0.1 & 1.0 & 0.7 & 1.3 & 0.7 & 2.1 & 4.0 & 1.7 & 2.8 & 1.5 \\
\hline Year-2 & 0.3 & 1.0 & 0.0 & 0.0 & 1.7 & 1.3 & 0.5 & 3.4 & 4.4 & 2.2 & 3.3 & 1.8 \\
\hline Year-1 & 0.8 & 1.7 & 0.8 & 1.5 & 1.0 & 1.2 & 0.8 & 1.9 & 4.2 & 1.7 & 2.8 & 1.3 \\
\hline Year 1 & 2.6 & 1.1 & 0.4 & 1.9 & 1.9 & 1.5 & 1.5 & 1.5 & 5.3 & 1.7 & 2.6 & 1.5 \\
\hline Year 2 & 2.6 & 5.6 & 0.6 & 1.5 & 1.9 & 3.7 & 1.5 & 1.5 & 6.5 & 2.6 & 3.2 & 2.1 \\
\hline Year 3 & 2.1 & 4.4 & 0.4 & 1.6 & 2.7 & 4.0 & 1.2 & 1.4 & 5.5 & 1.7 & 2.9 & 1.4 \\
\hline \multicolumn{13}{|c|}{$\begin{array}{l}\text { *Year }-3=3 \text { years until } 2 \text { years before the 'washout' month, Year }-2=2 \text { years until } 1 \text { year before the 'washout' month, Year }-1=1 \text { year before } \\
\text { the 'washout' month, Year } 1=1 \text { day after until } 1 \text { year after the neck trauma diagnosis, Year } 2=1 \text { year-2 years after neck trauma diagnosis, Year } \\
3=2-3 \text { years after the neck trauma diagnosis. } \\
\text { †ICD-10 chapter XII. } \\
\text { fICD-10 block F32, F41, F43. } \\
\text { \$ICD-10 M53.1 G44.0 G44.0 G44.3 F45.4 G44.2 R51 G44.1 H81.0 H81.1 H81.2 H81.3 H81.4 H81.8 H81.9 R } 42.9 \mathrm{~F} 40.0 \mathrm{H} 93 .\end{array}$} \\
\hline
\end{tabular}

The overall healthcare pattern before and after injury was similar for a majority of the cases, that is, highfrequent consulters preinjury also had high consultation frequency after the diagnosis of injury. We noted a distinct change among a subset of the low-frequent consulters. Consultations for musculoskeletal diseases, as well as mental disorders to some extent, were particularly common postinjury in this group. This group will be a special challenge for healthcare providers requiring that additional attention be paid to prevent the development of chronicity.

Previous reports have suggested that depression is a risk factor for neck pain. ${ }^{34}{ }^{35}$ However, neck pain may also be a risk factor for depression. ${ }^{30}$ Recently, concerns have been raised that poor health in general could be a risk factor for neck injury. ${ }^{28}{ }^{29}$ The explanation would be that poor health, especially mental conditions in combination with pharmaceuticals, would increase the risk of a car accident. ${ }^{28}$ Our results indicate that psychological distress is a common reason for physician healthcare consultation even before a diagnosis of acute neck injury. This tendency was maintained and even increased after injury.

In our study, we also made sensitivity analyses to separately evaluate the effects of educational level and propensity to seek healthcare, respectively. Also, after this process, we found increased healthcare utilisation among those with neck injury even before the injury. One may speculate about this increase, which can be

Table 4 Number (\%) of those with neck injury and references on sick leave or disability pension at the time of the neck-injury diagnosis, by total and stratified by low-frequent, frequent and high-frequent consulters before diagnosis of neck injury

\begin{tabular}{|c|c|c|c|c|c|c|c|c|}
\hline & \multicolumn{2}{|l|}{ All } & \multicolumn{2}{|c|}{ Low-frequent } & \multicolumn{2}{|c|}{ Frequent } & \multicolumn{2}{|c|}{ High-frequent } \\
\hline & Cases & References & Cases & References & Cases & References & Cases & References \\
\hline Disability pension & $96(6.7)$ & $337(5.8)$ & $11(2.9)$ & $30(1.5)$ & $22(3.8)$ & $103(4.5)$ & 69 (14.5) & $204(13.8)$ \\
\hline Sick leave & $58(4.0)$ & $151(2.6)$ & $7(1.8)$ & $22(1.1)$ & $11(1.9)$ & $43(1.9)$ & $40(8.4)$ & $86(5.8)$ \\
\hline
\end{tabular}


Figure 5 Mean number of sick days (sick leave and disability pension) for those with neck injury and references (A) and by preinjury consultation level for cases; low-frequent $(n=384)$, frequent $(n=583)$ and high-frequent $(n=476)(B)$.
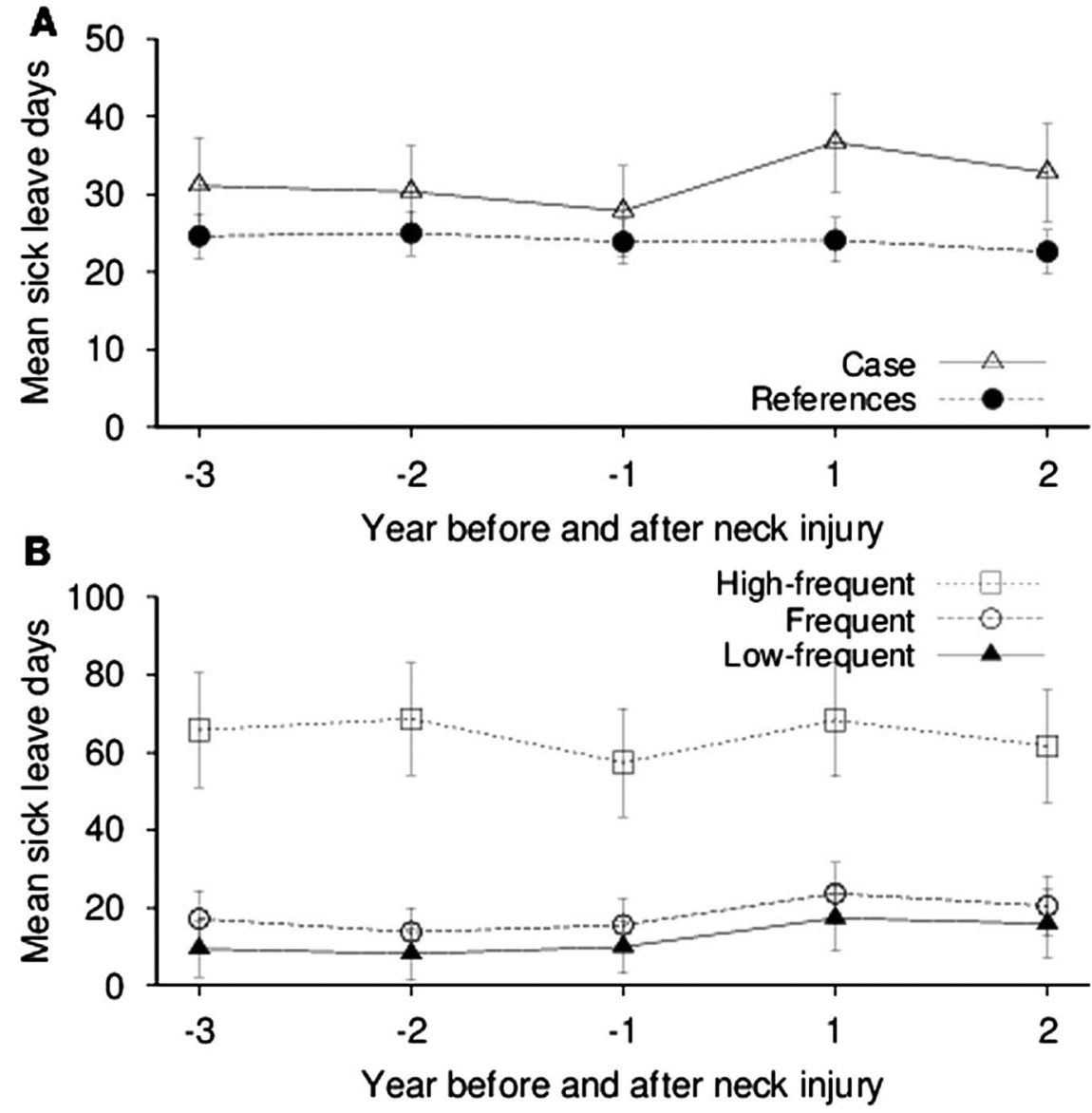

driven by a subgroup of individuals with a great need for healthcare due to specific characteristics before the injury and thus more vulnerable. It might also be individuals have a high propensity to consult for a wide variety of symptoms for other reasons. Patients diagnosed with neck injury are thus a heterogeneous group of patients, and it is important to recognise the different subsets within these patients. Some change from low-to-high frequent consulters while others remain low-frequent consulters even after a neck injury. Although there is no such thing as the right level of healthcare consultations that correspond to having recovered after neck injury, it seems like it is important to take previous healthcare consultation into account when determining an
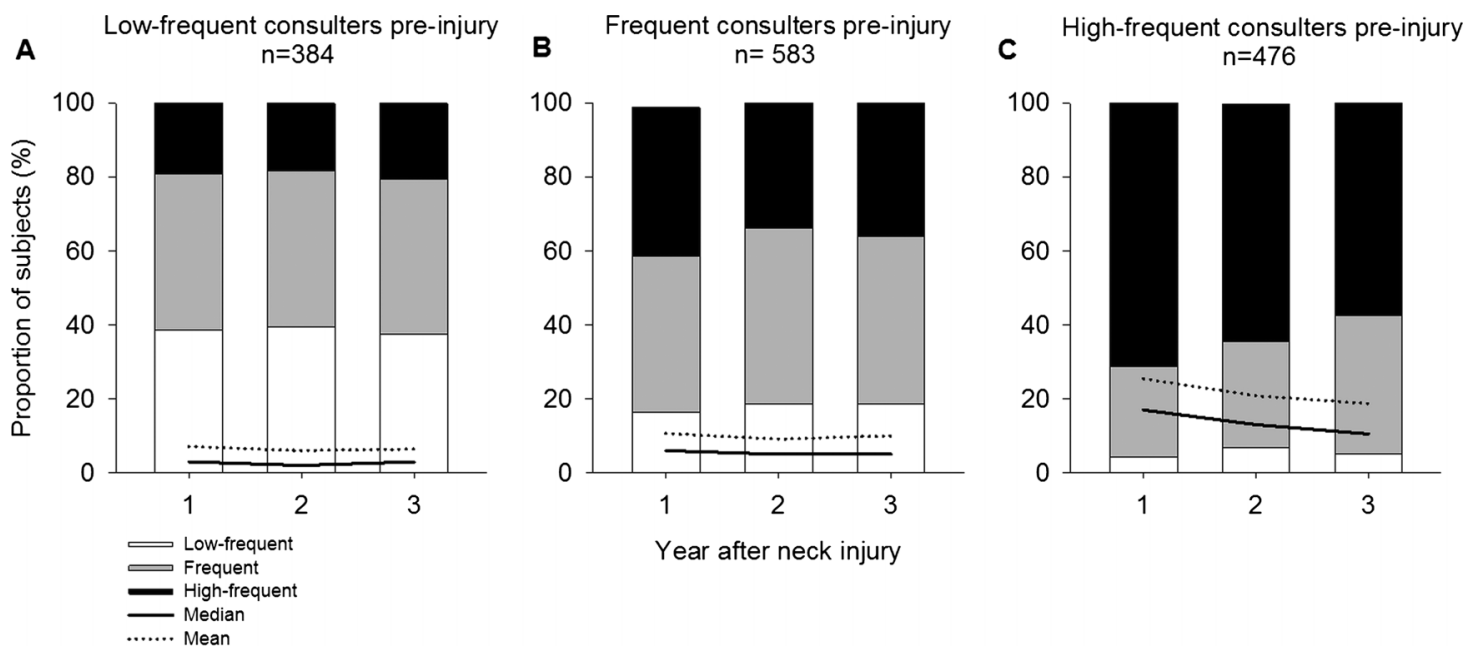

Figure 6 Annual postinjury consultation level stratified by preinjury consultation level; low-frequent $\leq 1$ consultation, frequent=2-8 consultations and high-frequent $\geq 9$ consultations per year pre neck injury. Interpretation (A), proportion of those with neck injury defined as low-frequent consulter pre neck injury that was defined as low-frequent, frequent and high-frequent consulters years 1,2 and 3 postneck injury. 
Table 5 Risk ratios (RR; $99 \% \mathrm{Cl}$ ) and attributable risk (AR) of transition between preinjury consultation level group per year after neck injury

\begin{tabular}{lllc}
\hline & Low-to-high frequent & Low/frequent-to-high frequent & Frequent-to-high frequent \\
\hline $\mathrm{RR}(99 \% \mathrm{Cl})$ & & & \\
Year post 1 & $2.27(1.63$ to 3.15$)$ & $2.00(1.72$ to 2.33$)$ & $1.80(1.52$ to 2.11$)$ \\
Year post 2 & $2.08(1.49$ to 2.91$)$ & $1.57(1.33$ to 1.84$)$ & $1.33(1.11$ to 1.58$)$ \\
Year post 3 & $1.76(1.29$ to 2.39$)$ & $1.59(1.36$ to 1.85$)$ & $1.44(1.21$ to 1.71$)$ \\
AR (\%) & & 16 & 18 \\
Year post 1 & 11 & 10 & 8 \\
Year post 2 & 10 & 11 & 11 \\
Year post 3 & 9 & & \\
\hline
\end{tabular}

individual's postinjury level. Therefore, we suggest, as an outcome in studies of healthcare utilisation, that preinjury levels should be taken into account.

Among those with neck injury who were low-frequent consulters, the proportion which was diagnosed by a physician with psychological distress or dizziness before the neck injury was in line with their reference individuals. However, postneck injury, this subgroup increased their consultation rates due to these conditions, corroborating prior reports. ${ }^{30}$ The proportion of patients with a physician's diagnosis of psychological distress rose relatively more postinjury than did the proportion of those with musculoskeletal disorders. This should be taken into account in treatment and rehabilitation based on the bio-psychosocial model. ${ }^{36}$ Interestingly, in the highfrequent group, the mean number of consultations due to mental disorders decreased while the mean number of consultations due to musculoskeletal disorders increased. One hypothesis would be that the former underlying cause of stress, anxiety or depression could be diverted to consultations regarding musculoskeletal symptoms after the injury.

Work disability was associated with the consultation pattern; high-frequent consulters had a higher mean number of sick days than the low-frequent consulters did. A relationship is expected between work disability and consultation frequency. The findings in our study emphasise the importance of highlighting and incorporating the early work and workplace interventions in the rehabilitation process to increase work ability in patients after neck injury. ${ }^{19} 333738$

Our study has some methodological limitations. We defined neck injury (whiplash) as recommended within the county by the ICD-10-SE injury diagnosis S13.4*. Apart from the recommendations, we also discussed the choice of diagnoses with physicians from the field. It is, of course, a possibility that some patients were missed while others potentially did not meet the 'whiplash injury' criteria. It is also possible that some physicians choose to diagnose differently, not following recommendations. It is, however, unlikely that these variations should follow any systematic direction, that is, any misclassification of exposure is likely to be non-differential with respect to outcomes. Further, the validity of this diagnostic code has not been tested, and the severity of the acute injury and its cause (car crash, sports injury, unclear cause etc) are likely to vary greatly. Still, the validity of other musculoskeletal diagnoses in SHR has been proven to be high and the diagnostic codes are derived directly from the electronic medical records as noted by the physicians. ${ }^{39}{ }^{40}$ In Sweden, everyone is entitled to free healthcare. Some practices are, however, private-run while being still public financed. This means that everyone is free to seek healthcare wherever they choose, and regardless of how the practice is run, private or public, in most cases the cost will be similar for the patient. For hospitalised care, only public options exist. In 2010, $60 \%$ of all patients sought only public care, $30 \%$ both public and private care and $10 \%$ sought only private care (not captured in SHR). Among those only seeking private care, $60 \%$ were women and the ages 30-50 years were overrepresented.

In our study, our aim was to compare participants with neck injury with population-based references. Although the overall pattern remained essentially the same, the exact differences between these groups changed slightly depending on how the references were sampled. The advantage of using population-based reference participants is that it allows us to take more general changes, for example, systematic changes in the healthcare system over time, into account. Further, we could estimate the increase in consultation frequency that could be considered to be attributable to the neck injury, for example, taking into account the regression to the mean phenomenon.

In summary, our study provides novel populationbased evidence on the consultation patterns preinjury and postinjury for patients diagnosed with acute neck injury. If studying the postneck injury healthcare consultation level, without stratifying for the preneck injury consultation level, one would miss the clear association between the preinjury and postinjury consultation frequency illustrating the heterogeneity of the patients. Our study also raises the importance of a subset of patients, the low-frequent consulters before, but highfrequent after a neck-injury episode, where neck injury is the most likely explanation. 
Contributors AJ, E-MM, HM and ME gave the original idea. AJ, JS, E-MM, HW, IFP and ME planned the study. AJ participated in data acquisition and data management and also conducted the statistical calculations and drafted the manuscript with input from ME. AJ, IFP and ME had access to the data. AJ, JS, E-MM, HW, IFP and ME interpreted the results. AJ, SJ, MEE, HW, IFP and $M E$ participated in the revision of the manuscript and approved the final version for submission. IFP and ME are the guarantors.

Funding The study was supported by grants from the regional health service authorities in Region Skåne, The Swedish Research Council (Vetenskapsrådet) (Grant number K2009-53X-21075-01), The Swedish Association for Survivors of Accident and Injury (RTP), and the Faculty of Medicine at Lund University. The funders had no role in the study design, data collection and analysis, decision to publish or preparation of the manuscript.

Competing interests None.

Ethics approval The Regional Ethical Review Board in Lund, Sweden (2011-431)

Provenance and peer review Not commissioned; externally peer reviewed.

Data sharing statement No additional data are available.

Open Access This is an Open Access article distributed in accordance with the Creative Commons Attribution Non Commercial (CC BY-NC 3.0) license, which permits others to distribute, remix, adapt, build upon this work noncommercially, and license their derivative works on different terms, provided the original work is properly cited and the use is non-commercial. See: http:// creativecommons.org/licenses/by-nc/3.0/

\section{REFERENCES}

1. Styrke J, Stålnacke B-M, Bylund P-O, et al. A 10-year incidence of acute whiplash injuries after road traffic crashes in a defined population in northern Sweden. P MR 2012;4:739-47.

2. Siegmund GP. What occupant kinematics and neuromuscular responses tell us about whiplash injury. Spine 2011;36:S175-9.

3. Jull G, Kristjansson E, Dall'Alba P. Impairment in the cervical flexors: a comparison of whiplash and insidious onset neck pain patients. Man Ther 2004;9:89-94

4. Ivancic PC, Panjabi MM, Ito S. Cervical spine loads and intervertebral motions during whiplash. Traffic Inj Prev 2006;7:389-99.

5. Adams MA, Freeman BJ, Morrison HP, et al. Mechanical initiation of intervertebral disc degeneration. Spine 2000;25:1625-36.

6. Jull GA, Sterling M, Curatolo $M$, et al. Toward lessening the rate of transition of acute whiplash to a chronic disorder. Spine 2011;36: S173-4

7. Carroll LJ, Holm LW, Hogg-Johnson S, et al. Course and prognostic factors for neck pain in whiplash-associated disorders (WAD): results of the bone and joint decade 2000-2010 task force on neck pain and its associated disorders. J Manipulative Physiol Ther 2009;32: S97-107.

8. Rebbeck T, Sindhusake D, Cameron ID, et al. A prospective cohort study of health outcomes following whiplash associated disorders in an Australian population. Inj Prev 2006;12:93-8.

9. Sterling M, Jull G, Kenardy J. Physical and psychological factors maintain long-term predictive capacity post-whiplash injury. Pain 2006;122:102-8.

10. Sterling M. Whiplash-associated disorder: musculoskeletal pain and related clinical findings. J Man Manip Ther 2011;19:194-200.

11. Sullivan MJL, Adams $\mathrm{H}$, Martel M-O, et al. Catastrophizing and perceived injustice: risk factors for the transition to chronicity after whiplash injury. Spine 2011;36:S244-9.

12. Andersen TE, Elklit A, Vase L. The relationship between chronic whiplash-associated disorder and post-traumatic stress: attachment-anxiety may be a vulnerability factor. Eur J Psychotraumatol 2011;2:5633. doi:10.3402/ejpt.v2i0.5633

13. Sterling M, Kenardy J, Jull G, et al. The development of psychological changes following whiplash injury. Pain 2003:106:481-9.

14. Treleaven J. Dizziness, unsteadiness, visual disturbances, and postural control: implications for the transition to chronic symptoms after a whiplash trauma. Spine (Phila Pa 1976) 2011;36:S211-17.
15. Field S, Treleaven J, Jull G. Standing balance: a comparison between idiopathic and whiplash-induced neck pain. Man Ther 2008;13:183-91.

16. Sterling M, Jull G, Vicenzino B, et al. Characterization of acute whiplash-associated disorders. Spine 2004;29:182-8.

17. Walton DM. Risk factors for persistent problems following acute whiplash injury: update of a systematic review and meta-analysis. J Orthop Sports Phys Ther 2009;39:334-50.

18. Kamper SJ, Rebbeck TJ, Maher CG, et al. Course and prognostic factors of whiplash: a systematic review and meta-analysis. Pain 2008;138:617-29.

19. Dufton JA, Bruni SG, Kopec JA, et al. Delayed recovery in patients with whiplash-associated disorders. Injury 2012;43:1141-7.

20. Walton DM, Pretty J, MacDermid JC, et al. Risk factors for persistent problems following whiplash injury: results of a systematic review and meta-analysis. J Orthop Sports Phys Ther 2009;39:334-50.

21. Crutebo S, Nilsson C, Skillgate E, et al. The course of symptoms for whiplash-associated disorders in Sweden: 6-month follow up study. J Rheumatol 2010;37:1527-33.

22. Holm LW, Carroll LJ, David Cassidy J, et al. Factors influencing neck pain intensity in whiplash-associated disorders in Sweden. Clin $J$ Pain 2007;23:591-7.

23. Kasch H, Qerama E, Kongsted A, et al. Clinical assessment of prognostic factors for long-term pain and handicap after whiplash injury: a 1-year prospective study. Eur J Neurol 2008;15:1222-30.

24. Spearing NM, Connelly LB, Nghiem HS, et al. Research on injury compensation and health outcomes: ignoring the problem of reverse causality led to biased conclusion. J Clin Epidemiol 2012;65:1219-26.

25. Cassidy JD, Carroll LJ, Côté P, et al. Does multidisciplinary rehabilitation benefit whiplash recovery?: results of a population-based incidence cohort study. Spine 2007;32:126-31.

26. Carroll LJ, Holm LW, Ferrari R, et al. Recovery in whiplash-associated disorders: do you get what you expect? J Rheumatol 2009;36:1063-70.

27. Scholten-Peeters GGM, Verhagen AP, Bekkering GE, et al. Prognostic factors of whiplash-associated disorders: a systematic review of prospective cohort studies. Pain 2003;104:303-22.

28. Mykletun A, Glozier N, Wenzel HG, et al. Reverse causality in the association between whiplash and symptoms of anxiety and depression: the HUNT study. Spine 2011;36:1380-6.

29. Wenzel HG, Vasseljen O, Mykletun A, et al. Pre-injury health-related factors in relation to self-reported whiplash: longitudinal data from the HUNT study, Norway. Eur Spine J 2012;21:1528-35.

30. Phillips LA, Carroll LJ, Cassidy JD, et al. Whiplash-associated disorders: who gets depressed? Who stays depressed? Eur Spine $J$ 2010;19:945-56.

31. Buitenhuis J, de Jong PJ, Jaspers JPC, et al. Work disability after whiplash: a prospective cohort study. Spine 2009;34:262-7.

32. Ozegovic D, Carroll LJ, Cassidy JD. What influences positive return to work expectation? Examining associated factors in a population-based cohort of whiplash-associated disorders. Spine 2010;35:E708-13.

33. Kasch H, Qerama E, Kongsted A, et al. The risk assessment score in acute whiplash injury predicts outcome and reflects biopsychosocial factors. Spine (Phila Pa 1976) 2011;36:S263-7.

34. Carroll LJ, Cassidy JD, Côté P. Depression as a risk factor for onset of an episode of troublesome neck and low back pain. Pain 2004;107:134-9.

35. Linton SJ. A review of psychological risk factors in back and neck pain. Spine 2000;25:1148-56.

36. Engel GL. The need for a new medical model: a challenge for biomedicine. Science 1977;196:129-36.

37. Reme SE, Shaw WS, Steenstra IA, et al. Distressed, immobilized, or lacking employer support? A sub-classification of acute work-related low back pain. J Occup Rehabil 2012;22:541-52.

38. Scott W, Trost Z, Milioto M, et al. Further validation of a measure of injury-related injustice perceptions to identify risk for occupational disability: a prospective study of individuals with whiplash injury. J Occup Rehabil. Published Online First: 26 January 2013. doi:10.1007/s10926-013-9417-1

39. Englund M, Jöud A, Geborek P, et al. Prevalence and incidence of rheumatoid arthritis in southern Sweden 2008 and their relation to prescribed biologics. Rheumatology (Oxford) 2010;49:1563-9.

40. Haglund E, Bremander AB, Petersson IF, et al. Prevalence of spondyloarthritis and its subtypes in southern Sweden. Ann Rheum Dis 2011;70:943-8. 